\title{
OCORRÊNCIA DE SURTO DE TUBERCULOSE CAUSADA PELO COMPLEXO Mycobacterium tuberculosis EM UMA CRIAÇÃO DE SUÍNOS
}

\author{
TUBERCULOSIS OUTBREAK IN A PIG FARM DUE TO Mycobacterium tuberculosis COMPLEX
}

\author{
Patrícia Schwarz $^{1}$, Luís Eduardo da Silva ${ }^{1}$, Alexandre Nolibus Marchetti², Fernando Pandolfo Bortolozzo ${ }^{2}$, \\ David Driemeier ${ }^{3}$, Cleandro Pazinato Dias², Joaquim Cezar Teixeira Fernandes ${ }^{4}$, Ivo Wentz ${ }^{2} \&$ \\ Marisa Ribeiro de Itapema Cardoso ${ }^{1}$
}

\begin{abstract}
RESUMO
A tuberculose continua sendo um importante problema de saúde pública, por ser uma zoonose que tornou-se reemergente devido, principalmente, a grande incidência entre portadores de imunodeficiências. A tuberculose, causada por micobactérias do grupo mamífero, em suínos criados em sistemas comerciais, é uma doença raramente encontrada. Neste trabalho, foram necropsiados três animais, provenientes de uma granja de suínos com aproximadamente 90 animais alimentados com resíduos alimentares. Alguns animais apresentavam tosse, anorexia e dor a palpação torácica. Linfonodos e fragmentos de vísceras com lesões macroscópicas foram submetidos a exames histopatológicos e microbiológico, além da tuberculinização em 62 animais adultos da propriedade. A prova dupla comparativa com tuberculinas mamífera e aviária foi realizada em 14 fêmeas da maternidade. Foram observadas lesões características de tuberculose (forma miliar e perolada) nos animais necropsiados no período de janeiro a março de 2000. O isolamento e cultivo foram compatíveis com Mycobacterium bovis. Na leitura das tuberculinizações foram observadas 49 reações positivas, sendo que nas duplas comparativas, 14 fêmeas foram reagentess apenas para tuberculina mamífera. Todos animais da propriedade foram encaminhados para o abate e coletados materiais para exame histopatológico e microbiológico e diagnóstico pela técnica de reação em cadeia pela polimerase (PCR). Após confirmação do diagnóstico de tuberculose foi elaborado um programa de eliminação do plantel, desinfecção e vazio sanitário. Este comunicado alerta para os riscos de tuberculose em suínos criados sem cuidados de biosseguridade, sobretudo aqueles alimentados com resíduos alimentares, e suas implicações na saúde pública.
\end{abstract}

Descritores: tuberculose, biosseguridade, resíduos alimentares, lesões.

\begin{abstract}
Tuberculosis continues being an important disease which demands attention from public health as it has emerged again with many occurrences between imunodeficients peoples. In this study, one female from a small farm with around 90 animals fed with food residues, were necropsied. The symptoms before death were cough, anorexia and thoracic touching. At the necropsy was collected lymph nodes and fragments from bowels with macroscopic lesions used for the diagnosis, which should be based on microscopic examination, isolation, and identification of Mycobacterium from these sites. Beside this exams, tuberculin testing was realized in sixty-two adults animals were. Tuberculin comparative testing with Mycobacterium bovis and Mycobacterium avium was realized in fourteen sows. It has been observed lesions of tuberculosis (miliary and pearllike) in the dead female and in all animals necropsied in this period. Forty-nine positives reactions were observed in the tuberculin testing readins and in the tuberculin comparative testing the fourteen sows got positive only for mammals tuberculin. Tuberculin testing of swine with subsequent slaughter of reactors, and depopulation of entire herds. Newly materials were collected for microbiological, microscopic examination and diagnosis using polimerase chain reaction technic. After diagnosis confirmation of tuberculosis, a program to depopulation of entire herds, disinfect and all-in, all-out technology. This communication makes aware of tuberculosis risks in swine farm out biossecurity and theirs problems from public health, mainly animals fed with food residues.
\end{abstract}

Key words: tuberculosis, reactions positives, all-in, all-out, residues.

${ }^{1}$ Setor de Medicina Veterinária Preventiva. ${ }^{2}$ Setor de Suínos. ${ }^{3}$ Setor de Patologia. ${ }^{4}$ Setor de Bacteriologia, Faculdade de Veterinária (FAVET) de Porto Alegre, Universidade Federal do Rio Grande do Sul (UFRGS).

CORRESPONDÊNCIA: P. Schwarz [e-mail: patriciaschwarz@brturbo.com ; Fax +55 513316 6132]. Av. Bento Gonçalves 9090; 91540-000 Porto Alegre, RS - Brasil. 


\section{INTRODUÇÃO}

Dentre as zoonoses, a tuberculose recebe especial atenção por parte das autoridades de saúde pública em nível mundial, por caracterizar-se reemergente num momento em que há uma grande incidência de casos entre portadores de imunodeficiências. A doença apresenta-se de duas formas: a generalizada e a localizada. A generalizada causada por micobactérias do grupo mamífero, provoca emagrecimento progressivo, pneumonia e lesões calcificadas em vários órgãos, esta forma é rara nas criações comerciais de suínos [2]. A manifestação em suínos também pode ser de forma localizada, causada por micobactérias atípicas, incluindo-se o Mycobacterium avium, $M$. intracellulare, $M$. fortuitum, $M$. scrofulaceum e M. silvaticum [4]. A contaminação dos suínos com o grupo de micobactérias mamíferas pode ocorrer a partir da alimentação dos mesmos com subprodutos bovinos, provenientes da alimentação de humanos e doentes ou por resíduos de frigorífico não adequadamente cozidos, bem como resíduos de restaurantes e hospitais [10]. O tratamento de animais reagentes à tuberculinização não é recomendado devido aos riscos sanitários, alto custo e baixa eficiência [2]. Em caso de diagnóstico positivo para tuberculose o plantel deve ser eliminado e o repovoamento da criação deve adotar normas de biosseguridade que visem à prevenção de uma nova contaminação, como: controle de vetores, qualidade da água, movimentação de pessoal e reposição de animais [3].

Este trabalho tem por objetivo descrever um surto de tuberculose ocorrido em uma criação de suínos que utiliza resíduos alimentares de restaurantes na alimentação dos animais.

\section{MATERIAIS E MÉTODOS}

A granja que alojava aproximadamente 90 suínos, entre reprodutores, matrizes de diferentes idades e leitões, se localizava no Município de Viamão (RS). Os animais eram criados de forma semi-confinada e sua alimentação era baseada em resíduos cozidos de restaurantes. Apenas as fêmeas lactantes e os leitões da creche recebiam, adicionalmente, ração comercial, própria para cada categoria animal. Em outubro de 1999 uma fêmea da propriedade morreu após apresentar sinais de dor à palpação torácica, tosse e anorexia. Na necropsia foram coletados linfonodos e fragmentos de vísceras que apresentavam lesões macroscópicas sugestivas de tuberculose $\mathrm{O}$ material foi enviado para exame histopatológico e microbiológico. As técnicas empregadas foram a coloração de Ziehl-Neelsen, em esfregaços de tecido, exame histológico convencional e semeadura em ágar sangue ovino e meio Löwenstein-Jensen com e sem glicerol [1]. Enquanto era aguardado o resultado do exame microbiológico, realizou-se a prova de tuberculina em 62 animais adultos desta propriedade. Em 14 fêmeas, que estavam alojadas na maternidade, foi realizada a prova dupla comparativa com tuberculinas mamífera e aviária, enquanto nos demais realizou-se a prova simples. A aplicação da tuberculina e a leitura foi feita como recomendado.

Posteriormente, animais em que foram encontradas lesões compatíveis com tuberculose na necropsia ou ao abate, tiveram linfonodos e vísceras com lesões macroscópicas coletadas e submetidas ao exame histopatológico e ao diagnóstico pela Reação em Cadeia da Polimerase (PCR) conforme descrito [7].

\section{RESULTADOS}

Nas necropsias, foram observadas lesões típicas de tuberculose, caracterizadas por nódulos de grandes dimensões, muitos dos quais fortemente mineralizados distribuídos em diversos tecidos principalmente linfonodos, tonsilas, intestino e útero. A forma miliar era evidente em órgãos parenquimatosos como fígado, baço e pulmão e a forma perolada em serosas da pleura e do peritônio. Ao exame microscópico das amostras, foi diagnosticado bacilos álcool ácido resistentes (BAAR) [8]. Após 15 dias de incubação, obteve-se crescimento de colônias pequenas, brilhosas, não cromógenas com crescimento inibido por glicerol, segundo [6], compatíveis com características de Mycobacterium bovis. Na leitura das tuberculinizações foram observadas 49 reações positivas (79\%) dos 62 animais tuberculinizados, sendo que nas duplas comparativas, todas as 14 fêmeas foram reagentes apenas para tuberculina mamífera. Dos animais reagentes a tuberculinização, dois que apresentavam mau estado nutricional, foram sacrificados e mais uma fêmea morreu. Estes animais, além das lesões anteriormente descritas, apresentavam mastite tuberculosa. Todos os animais foram necropsiados, procedendo-se da mesma forma como no primeiro animal examina- 
do. Após o diagnóstico conclusivo, todos suínos da propriedade foram eliminados. Destes, 57 foram abatidos em um frigorífico no Município de Viamão, enquanto os demais foram sacrificados e enterrados na propriedade. Metade de duas meias-carcaças e quinze vísceras foram condenadas pelo Serviço de Inspeção Estadual. O exame histopatológico, realizado após os abates, evidenciou focos de necrose caseosa múltiplos com mineralização e foram observados ainda bactérias gram-positivas. A partir dos animais abatidos, foi novamente realizado o isolamento compatível com M. bovis. O diagnóstico realizado pela técnica de PCR apresentou resultado positivo para Complexo Mycobacterium tuberculosis (M. tuberculosis), ou seja, M. bovis ou Mycobacterium tuberculosis.

\section{DISCUSSÃO}

Com o surgimento da Síndrome de Imunodeficiência Adquirida, vem-se observando, tanto em países desenvolvidos como nos países em desenvolvimento, um crescente número de casos notificados de tuberculose. A associação com o vírus da imunodeficiência adquirida constitui, nos dias atuais, um sério problema de saúde pública, podendo levar ao aumento da morbidade e mortalidade pela tuberculose, em muitos países [10]. Locais com alta prevalência destes agentes contribuem para a infecção de humanos imunodeficientes. Apesar da maioria dos casos em humanos ser causado pelo M. tuberculosis; os casos cuja etiologia é o $M$. bovis também podem alcançar índices importantes em algumas regiões. Estes casos estão associados principalmente à contaminação pela ingestão de leite não pateurizado proveniente de bovinos doentes. O suíno como fonte de contaminação para humanos é mais rara, porém em indivíduos em contato com plantéis infectados pode assumir importância. Da mesma forma a partir de carne e subprodutos provenientes de animais com lesões, pode ocorrer a contaminação da população em geral.

Neste trabalho, o isolamento e cultivo foram compatíveis com M. bovis, cuja infecção pode apresentar lesões generalizadas [5], características da tuberculose clássica. A tuberculose mamífera em suínos tem algumas peculiaridades de causar acentuada calcificação em relação a forma aviária a qual apresenta necrose caseosa mas as áreas de mineralização são menores [10]. A presença de áreas de mineralização foi extensa nos casos descritos em todas as áreas com lesões. Imediatamente após a primeira suspeita de diagnóstico compatível com tuberculose, a venda de animais foi suspensa. Posteriormente, com a confirmação do diagnóstico, os mesmos foram encaminhados para o abate, visando um programa de eliminação do plantel, desinfecção das instalações, seguidos de vazio sanitário. A desinfecção consistiu da remoção de todas estruturas de madeira e sua incineração, seguida de remoção dos resíduos sólidos aderidos, lavagem de paredes e pisos e finalmente desinfecção física por calor. O período de vazio sanitário foi de aproximadamente 5 meses.

A origem do surto diagnosticado não pode ser completamente elucidada, porém algumas hipóteses podem ser levantadas. A primeira delas seria uma contaminação remanescente na propriedade a partir de gado leiteiro, existente anteriormente na propriedade, e que teve diagnóstico positivo para tuberculose bovina. Além disso, a propriedade teve um funcionário com diagnóstico positivo para tuberculose, que há aproximadamente dois anos havia trabalhado no antigo tambo deste local. Em segundo lugar, o fato de os animais serem alimentados com restos de restaurantes; caso os mesmos não tenham sofrido tratamento térmico adequado, podem ter sido fonte de contaminação. Finalmente a propriedade apresentava livre circulação de pessoas e animais na propriedade, o que também não está de acordo com normas de biosseguridade. Atualmente, as pessoas envolvidas na criação são submetidas a exames médicos periódicos e somente entram em contato com os animais quando comprovadamente imunizadas com BCG. O repovoamento de suínos adotou melhores medidas de biosseguridade [9], como controle da origem dos animais e melhor processamento dos alimentos, visando a prevenção de uma possível contaminação do plantel. Portanto, ainda é necessário o desenvolvimento e execução de programas de controle, através de ações de diagnóstico e tratamento de indivíduos e a eliminação de animais portadores e com sintomatologia clínica de tuberculose. Pois, o surto relatado, alerta para a vigilância epidemiológica necessária para os casos de zoonoses como a tuberculose.

\section{CONCLUSÕES}

O diagnóstico de tuberculose é confirmado através das provas alérgicas de tuberculina, achados patológicos, microbiológicos e PCR. O presente comunica- 
do alerta para os riscos de tuberculose em suínos criados sem cuidados de biosseguridade, sobretudo aqueles alimentados com resíduos alimentares, e suas implicações na saúde pública, colocando as pessoas que trabalham nessa atividade e aquelas que a seus produtos têm acesso em iminente risco de infecção.

\section{REFERÊNCIAS}

1 Benenson A.S. 1992. El Control De Las Enfermidades Transmisibles En El Hombre. 15. ed. Washington: OMS, $618 \mathrm{p}$.

2 Biberstein E.L. \& Zee Y.C. 1990. Review Of Veterinary Microbiology. Oxford: Blackwell Scientific Publications, 612p.

3 Carter G.R. \& Cole J.R. 1999. Diagnostic Procedures. In: Veterinary Bacteriology and Mycology. 5th edn. San Diego: Academic Press Inc., 620p.

4 Jubb K.F., Kennedy P.C. \& Palmer N. 1992. Pathology of Domestic Animals. 4th edn. San Diego: Academic Press, v. 2, pp.641-650.

5 Moore C. 1992. Biosecurity and minimal disease herds. Veterinary Clinical North American Food Animal Practices. 8: 461-74.

6 Morés N., Silva V.S. \& Dutra V. 1997. Linfadenite Tuberculóide O Que Pode Ser Feito Para Seu Controle. In: Instrução Técnica Para o Suinocultor. Concórdia: Embrapa CNPSA. Número 4, 2p.

7 Park Do Y., Kim J.Y., Choi K.U., Lee J.S., Lee C.H., Sol M.Y. \& Suh K.S. 2003. Comparison Of Polymerase Chain Reaction With Histopathologic Features For Diagnosis Of Tuberculosis In Formalin-Fixed, Paraffin-Embedded Histologic Specimens. Archives of Pathology Laboratory Medicine. 127: 326-330.

8 Quinn P. J., Carter M.E., Markey B. \& Carter G.R. 1994. Clinical Veterinary Microbiology. London: Wolfe, 648p.

9 Sobestiansky J., Barcellos D., Mores N., Carvalho L. F. \& Oliveira S. 1999. Micobacterioses. In: Clínica e Patologia Suína. 2. ed. Goiânia: Embrapa, pp. 290-294.

10 Thoen C. O. 1994 Tuberculosis. In: Leman A.D., Straw B.E., Mengelling W.L., D’ Alaire S. \& Taylor D. (Eds). Diseases of swine. 7th edn. Ames: Iowa State University, pp. 617-626. 